\title{
Bolhas Imobiliárias em Destinos Turísticos: uma exploração preliminar ${ }^{1}$
}

\author{
Real State Bubbles in Touristic Destinations: some preliminary regards
}

Burbujas de la Vivienda en los Destinos Turísticos: una exploración preliminar

\author{
Márcia Maria Oliveira Bezerra ${ }^{2}$ \\ Maria do Livramento Miranda Clementino ${ }^{3}$
}

\begin{abstract}
Resumo
$\mathrm{O}$ artigo analisa as condições de emergência de bolhas imobiliárias em destinos turísticos que fazem parte dos circuitos de comercialização das grandes operadoras internacionais de turismo. Inicialmente aborda a literatura que trata das temáticas especulação e bolhas de ativos e sua consideração no setor imobiliário, definindo os indicadores a partir dos quais é possível identificar a emergência de uma bolha imobiliária em um dado espaço. Examina os fatores associados às condições de demanda e oferta do setor em uma destinação turística e adota a hipótese de ser o turismo internacional um mecanismo propagador das bolhas de imóveis que estejam ou tenham ocorrido nos grandes centros emissores desses visitantes. Conclui que o movimento especulativo nos mercados imobiliários desses destinos deve ser reforçado por determinantes internos, como a demanda interna, que tende a ser fortemente impulsionada pelo movimento especulativo, assim como pela expansão do crédito no interior desses territórios, decorrente da política monetária em vigor.
\end{abstract}

Palavras-chaves: bolhas imobiliárias; turismo; crédito.

\section{Abstract}

The article analyzes the emergence conditions for real estate bubbles in tourist destinations that are part of the marketing channels of large international tour operators. Initially it discusses the literature dealing with speculation and asset bubbles themes in the real estate industry, defining the indicators from which it is possible to identify the emergence of a housing bubble in a given space. It examines the factors associated with demand and supply conditions in the industry in a tourist destination and adopts the hypothesis of an

\footnotetext{
${ }^{1}$ Com agradecimentos ao apoio financeiro dado pelo CNPQ.

2 Doutora em Economia. Professora Assistente do Departamento de Economia da UFRN. E-mail: marciabezerra@ufrnet.br.

${ }^{3}$ Doutora em Economia pelo IE-UNICAMP. Professora Titular do Departamento de Políticas Públicas da UFRN. Coordenadora do Núcleo Natal do INCT- Observatorio das Metrópoles. E-mail: clement@ufrnet.br.
} 
international tourism propagative mechanism of real estate bubbles that are occurring or have occurred in major centers of origin of these visitors. It concludes that the speculative movement in real estate markets of these destinations must be reinforced by internal determinants, such as domestic demand, which tends to be strongly driven by the speculative movement, as well as the credit expansion within these areas, due to monetary policy in force.

Keywords: real state bubbles; tourism; credit.

\section{Resumen}

El artículo analiza las condiciones de aparición de burbujas inmobiliarias en los destinos turísticos que forman parte de los canales de comercialización de los grandes operadores internacionales. Inicialmente analiza la literatura que trata temas de la especulación y las burbujas de activos en la industria de bienes raices, haciendo la definición de los indicadores de los que se puede identificar el surgimiento de una burbuja de la vivienda en un espacio dado. En él se examinan los factores asociados con las condiciones de oferta y demanda en la industria en un destino turístico y si adopta la hipótesis de el turismo internacional como un mecanismo de difusión de las burbujas inmobiliarias que están o han estado en los principales emisores de estos visitantes. Se concluye que los movimientos especulativos en los mercados de la propiedad de estos destinos deben ser reforzados por los determinantes internos, tales como la demanda interna, que tiende a ser fuertemente impulsada por los movimientos especulativos, así como la expansión del crédito dentro de estas áreas, debido a la politica monetaria en vigor.

Palabras claves: burbujas de bienes raices, turismo, crédito.

\section{Introdução}

Kindleberger (2000) observa que ao longo do tempo diferentes ativos serviram de objeto de especulação. Ele cita, entre outros exemplos, aplicações em terras, prédios de escritório, centros comerciais, condomínios e casas que, em determinados períodos da história, transformaram-se em verdadeiras manias. Em anos mais recentes, é possível encontrar estudos que tratam de movimentos especulativos com imóveis que pelas intensidades alcançadas receberam a denominação de bolhas imobiliárias. Na literatura sobre o assunto tem recebido destaque a bolha imobiliária japonesa (fins dos anos oitenta), a coreana (início dos anos noventa) $)^{4}$, a norte-americana e de outros países europeus $(2008)^{5}$.

\footnotetext{
${ }^{4}$ A respeito das bolhas imobiliárias japonesa e coreana ver Dymski (1998).
} 
Em alguns países, a emergência de um boom imobiliário esteve também fortemente vinculada à expansão do turismo, notadamente, à entrada de turistas estrangeiros em seus territórios. Podem ser citados como exemplos o que aconteceu com algumas regiões da Espanha, com alguns países do sudoeste asiático e após o tsunami de 2004, com algumas capitais do litoral do Nordeste brasileiro. O intenso movimento de compra de terrenos e imóveis, bem como a construção de grandes empreendimentos imobiliários por europeus no litoral nordestino foi tema de várias reportagens veiculadas, inclusive, em jornais estrangeiros. De modo geral, muitos turistas combinavam interesses de aplicação com o de constituir uma segunda residência nesses locais, o que levou ao incremento substancial dos preços dos terrenos e imóveis construídos.

Diversos trabalhos, em diferentes níveis de abstração, trataram de explicar o surgimento de bolhas de ativos e responder a indagação acerca dos limites de expansão de seus mercados que, uma vez atingidos, culminariam com seu "estouro". Uma referência importante para o tratamento dessa temática é o estudo desenvolvido por Dymski (1998, p. 92-93), que conclui serem as bolhas "fenômenos inerentemente espaciais", que costumam ocorrer em "economias de alto crescimento". Estas últimas se caracterizariam por crescer "mais rápido do que as economias nas regiões e países adjacentes". Para o autor, as economias de alto crescimento podem ser definidas como economias de boom quando "esse alto crescimento é imputável parcial ou integralmente aos significativos e sustentados influxos de trabalho e riqueza". (DYMSKI, 1998, p. 92)

Com base nessas considerações, Dymski conclui que uma "economia de boom" se transforma em uma "economia de bolha" quando o influxo de riqueza na mesma supera a possibilidade de criação de ativos de capital. Esta transformação é praticamente inevitável quando o influxo de riqueza ao crescer a taxas superiores ao incremento populacional produz reflexos nos preços dos ativos locais.

É certo que a formação dos preços dos imóveis em um determinado destino turístico, como em qualquer mercado, depende aprioristicamente dos fatores associados às condições de oferta e demanda. Contudo, é preciso desvendar quais são os condicionantes externos e

\footnotetext{
${ }^{5}$ Sobre as bolhas imobiliárias americana e de outros países desenvolvidos ver Macedo e Silva (2006) e Vidotto (2008).
} 
internos de um local turístico que o tornam sujeito à contaminação de bolhas de ativos que estejam ocorrendo nos mercados emissores de seus visitantes.

Este artigo tem a propósito de explorar em linhas gerais os fenômenos associados à formação de bolhas imobiliárias em destinos turísticos consolidados que atraem sistematicamente turistas estrangeiros aos seus territórios. Ele considera que quando os condicionantes internos são favoráveis ao aquecimento do mercado imobiliário local, o turismo internacional pode ser um mecanismo propagador de uma bolha imobiliária que esteja acontecendo nas economias dos principais países emissores.

A questão a ser tratada é em que contexto emerge uma bolha imobiliária em um destino turístico, quais são os condicionantes de sua sustentação e as possibilidades de sua ruptura. Para entender e abordar esse fenômeno recorre-se à bibliografia que trata do fenômeno da especulação e das bolhas e da organização do setor turístico. Em seguida serão definidos os indicadores que podem servir de base para que se possa aferir efetivamente se existe bolha de imóveis em um destino turístico. Posteriormente serão examinados os fatores relacionados à oferta e demanda do mercado imobiliário.

\section{A Especulação e as Bolhas}

Como forma de explorar inicialmente a temática em questão pode ser citada a obra de Kindleberger (2000) e o exame que a mesma faz dos ciclos econômicos, centrado na investigação das fases de booms e das crises financeiras, chamadas de crash. Para o autor, os ciclos de crescimento têm início com determinadas mudanças no ambiente que promovem novas oportunidades de lucro, proporcionadas pela transação com um determinado ativo. Em certas ocasiões, a procura por esse ativo é tão intensa que sua aquisição se transforma em uma espécie de mania entre os agentes.

De modo geral, o autor propõe que o crescimento da demanda é sustentado pela forte expansão do crédito, principalmente do crédito bancário, e pode estimular o aumento da produção. Neste processo, os agentes mais ricos convertem os diferentes tipos de ativos que possuem em dinheiro para garantir a compra do ativo objeto de valorização, outros recorrem ao endividamento para financiar a aquisição do mesmo. Em algum momento, a alta nos 
preços desse ativo atingirá um patamar que vai induzir determinados agentes a saírem do mercado, realizando seus lucros. Tal movimento pode ensejar a saída de outros participantes e a desistência dos futuros entrantes, contribuindo para gerar um movimento abrupto de venda que provocará uma queda considerável no preço do ativo - é a fase de pânico, que tende a gerar o crash.

Quando a demanda pelo ativo que está se valorizando é fortemente motivada pelo objetivo de revenda do mesmo, o propósito do agente é, segundo Kindleberger, especular. Para este autor, a especulação e o lucro configuram situações anormais, pautadas por atos irracionais. $\mathrm{O}$ crescimento da demanda do ativo é ampliado significativamente pela ocorrência simultânea: i) do aumento no número de empresas e particulares que procuram adquiri-lo; e ii) pela entrada no circuito de compra de parte da população que não costuma se envolver em tais "aventuras", mas que não resiste ao desejo de enriquecer. Neste caso, o comportamento dos agentes pode gerar 'manias' ou 'bolhas'. De acordo com o autor “a palavra mania enfatiza a irracionalidade; bolha prenuncia estouro". Definindo esse último estágio em seu livro, ele conclui: "uma bolha é um movimento de preço para cima numa série ampliada que depois implode. Uma bolha negativa ampliada é um crash". (KINDLEBERGER, 2000, p.19).

Conforme foi aludido na introdução, outro trabalho que pode oferecer contribuições importantes para o entendimento do assunto aqui tratado é Dymski (1998) que analisa a formação de bolhas em uma perspectiva espacial, considerando os casos de crises financeiras no leste asiático e na Califórnia. Ele critica as interpretações das bolhas asiáticas que têm por base a visão de distanciamento dos preços dos ativos de seus valores fundamentais de equilíbrio. $\mathrm{O}$ autor rechaça também a análise que vê as crises a partir da abordagem de problemas de incentivo em contexto de informação assimétrica. ${ }^{6}$

Para examinar a formação de bolhas de ativos e as crises financeiras que se seguem ao seu "estouro", o autor propõe um enfoque que privilegie a base metodológica desenvolvida por Keynes na Teoria Geral, ou seja, em uma perspectiva que considere a "interação entre incerteza e forças econômicas estruturais". Neste sentido, ele enfatiza que para Keynes, "as

\footnotetext{
${ }^{6}$ Nessa perspectiva, projetos potencialmente mais arriscados teriam sido financiados sem que os emprestadores do leste asiático exercessem "a vigilância necessária" para enfrentar o problema do risco moral.
} 
pessoas não podem ser totalmente racionais, pois a informação paramétrica não está disponível para ser apropriada.” (DYMSKI, 1998, p. 83)

Para o referido autor, os fatores determinantes de uma economia de "alto crescimento" definida no item anterior podem ser: a existência de trabalho bastante qualificado e um "grande volume de capital moderno", que permite a formação de um estoque de capital com elevados níveis de produtividade; e/ou os "influxos sustentados de fatores de produção, inclusive injeções de riquezas" (DYMSKI, 1998, p. 92), nos quais se podem incluir os fenômenos da imigração e da própria migração, quando se trata de uma região dentro de um país.

Quando a "economia de boom" se transforma em uma "economia de bolha", a bolha de ativos tende a estourar e a impor pesadas perdas para os seus detentores. E como chama atenção o próprio autor, a extensão da perda envolve vários outros agentes, pois impossibilita ou reduz substancialmente a capacidade de liquidação dos compromissos que foram assumidos pelos compradores dos ativos para financiar suas posições. A reação dos bancos ao aumento de suas fragilidades financeiras contribui para a restrição de liquidez da economia, gerando o ambiente favorável a ocorrência da deflação de ativos. Neste sentido, Dymski (1998) conclui:

\begin{abstract}
A combinação entre incerteza e uma abordagem estrutural para economias com fronteiras, a constatação de que na maior parte das economias há entradas ou saídas de riqueza e/ou de trabalho, e ainda o reconhecimento de que a capacidade de criação de ativos varia enormemente, conduzem à conclusão de que as bolhas de ativos surgem por todos os lugares. Assim, as economias de boom são lugar-comum, e não eventos raros; as economias de boom têm forte propensão a serem, por conseqüência, financeiramente frágeis. (DYMSKI, 1998, p. 91).
\end{abstract}

$\mathrm{Na}$ verdade, a introdução da incerteza na construção de premissas que orientam a tomada de decisão dos agentes coloca sérias dificuldades à decomposição da variação de preços entre componentes que são explicados por mudanças nos "fundamentais" e os componentes de bolha. Se tudo é expectativa, inclusive os fundamentais, toda aplicação em ativo é baseada em expectativa de ganho futuro. Como observa Davidson: “A especulação pode apenas ocorrer em um mundo incerto, onde mudanças nos fatores subjacentes à relação de oferta e demanda não pode nunca ser antecipada com certeza" (DAVIDSON, 1978, p. 108). 
$\mathrm{Na}$ referida obra, Davidson analisa teoricamente os fatores que afetam o desempenho da economia por meio dos mercados spot e forward e de seus respectivos preços. Em sua perspectiva, em um mercado spot define-se um preço que permite alocar o estoque de uma mercadoria existente, resultante de períodos de produção anteriores (isto é, não há produção nova, os ativos transacionados já existem no mercado), de modo que não haja excesso de oferta e de demanda. No mercado forward pode haver alteração da quantidade de bens decorrente do fluxo de produção no período curto $^{7}$ e, em algumas situações, o preço forward corresponde ao preço do fluxo de oferta do curto período.

Davidson relaciona as condições para que um bem possua mercados spot e forward bem organizados, que incluiriam ter o mesmo ampla demanda, ser padronizado, apresentar um elevado grau de substitutibilidade "entre velhos e novos itens", ter um fluxo anual de oferta pequeno quando comparado ao volume de estoque existente, ser durável, e "ser valorizado em proporção ao seu volume". Ele observa, contudo, que o desenvolvimento dos mercados spot e forward estão condicionados à existência das duas características: o fluxo anual de produção representar uma pequena proporção do estoque de bens existentes e desse bem ser durável. As demais seriam condições essenciais para que esses mercados se tornassem "bem organizados e perfeitos". ${ }^{8}$ Em geral, os contratos associados aos mercados forward implicam na realização de entrega futura do bem contra pagamento em data especificada também no futuro. (Davidson, 1978, p. 94).

A partir da consideração dos preços forward e spot, o autor pretende examinar os mecanismos de estímulos à produção e os efeitos dessa atividade produtiva sobre os preços. Ele sugere que, em se tratando de um período curto, o preço spot seja considerado o preço do período de mercado, enquanto o preço forward deva ser visto como "o preço que o empresário considera no início do período de produção". Ressalta-se que o comportamento da demanda tem impacto sobre o a variação do estoque e o preço spot, afetando as decisões de produção. Assim, caso o preço spot supere o preço forward, a diferença entre os mesmos induz a

\footnotetext{
${ }^{7}$ Período curto em termos analíticos corresponde ao período de produção (necessário para fabricar a mercadoria) mais o período de mercado (o tempo necessário para vender a mercadoria produzida). Macedo e Silva (1999)

${ }^{8}$ Davidson explica a baixa organização de mercados spot para bens de capital pela "carência de uniformidade entre as unidades de capital fixo", que imporia elevados custos de transação à atuação de alguma instituição para operar como comprador ou vendedor residual no mercado. Assim, empresários que têm a intenção de aumentar a capacidade produtiva de suas empresas costumam recorrer a mercados forward, evitando comprar um "equipamento de segunda mão".
} 
'recomposição de estoques' (situação de backwardation), mas se o preço forward for superior ao preço spot, a elevação dos níveis de estoques, fruto de uma demanda insuficiente, irá "desestimular a produção" (situação de contango no mercado).

A comparação entre o preço forward e o preço spot serve de base para que o empresário tome sua decisão de produção. Enquanto a decisão de investimento exigirá que o mesmo estabeleça uma análise comparativa entre o preço forward e o preço do fluxo de oferta de longo prazo (no sentido microeconômico, que leva em conta a variação na capacidade produtiva). Contudo, no caso das empresas produtoras de bens de capital, as decisões de produção têm conseqüências macroeconômicas, pois afetam a capacidade produtiva da economia.

Davidson observa que os arranjos institucionais que sustentam os mercados spot e forward em algumas economias capitalistas desenvolvidas encorajam os homens a especular, e o resultado de tal processo pode ser a formação de excesso de capacidade produtiva. Assim, "o esforço resultante da economia para retificar o erro no curto período de tempo pode ter um impacto substancial sobre o emprego, o produto, os preços, e a distribuição de perdas e/ou ganhos inesperados." (DAVIDSON, 1978, p.110).

Como material bibliográfico exploratório para o desenvolvimento do trabalho podem ser utilizados ainda trabalhos no campo do turismo. Os estudos que servirão de base à reflexão são Cruz (2001), Fonseca (2005), Lage e Milone (1991) e Mendonça e Bezerra (2007). Inicialmente, convém observar que a oferta turística de um determinado destino é composta por diferentes segmentos que apresentam diferenças quanto ao porte de seus empreendimentos. O conjunto de empresas que compõem a chamada "indústria do turismo" efetua negócios relacionados às atividades de hospedagem, transporte, restaurante, operadoras de viagens, agências de viagem e entretenimento, e serviços de atendimento ao turista. A realização de tais atividades, porém, requer a existência prévia de infraestrutura básica e turística, especialmente em destinos voltados para o mercado internacional, pois a falta de suporte adequado desses serviços pode implicar na criação de pontos de estrangulamento ao desenvolvimento do turismo e/ou obsolescência da destinação.

A interdependência dos negócios turísticos permite que os mesmos sejam tratados como elos de uma cadeia, cujo produto final é o pacote de viagem, que integra em um mesmo contrato a venda de diferentes serviços oferecidos ao visitante por empresas de portes distintos. Há forte 
heterogeneidade no setor, entre os diferentes elos e mesmo entre empresas que prestam o mesmo tipo de serviço: cadeias hoteleiras podem operar ao lado de grandes hotéis independentes e mesmo de pequenas pousadas; empresas que integram as redes internacionais de fast food podem localizar-se ao lado de pequenos restaurantes, pequenas agências de viagens podem integrar um grande conglomerado turístico ou serem independentes. $\mathrm{Na}$ verdade, à exceção dos transportes aéreos e das grandes operadoras de turismo, a oferta turística é realizada por uma grande quantidade de micro e pequenas empresas ${ }^{9}$.

Para que uma destinação possa atrair turistas é essencial, contudo, que possua os meios de hospedagem e serviços de alimentação em seu território ${ }^{10}$; as demais atividades podem ser desenvolvidas por empresas instaladas em outras regiões, que incluem tal destino nos seus mercados de vendas. Como o turismo é um bem de alta elasticidade-renda (superior a 1), a demanda pelos serviços oferecidos pelas empresas e os lucros das mesmas aumentam mais que a média da economia em períodos de crescimento econômico; o oposto dando-se em períodos de contração econômica.

Outra característica que pode ser observada é o fenômeno da sazonalidade dos negócios turísticos, assim, em períodos de alta estação, aumenta substancialmente o número de visitantes que acorrem a uma dada destinação, enquanto que nas fases de baixa estação caem a demanda e as receitas dos negócios turísticos. Essa questão pode trazer um problema maior para empresas que têm pesados custos fixos distribuídos ao longo do ano, como os hotéis, pois implica na concentração de receitas em alguns períodos, enquanto as despesas se distribuem ao longo do tempo, exigindo um maior controle do fluxo de caixa desses empreendimentos $^{11}$. Outro aspecto que deve ser considerado, é que não há possibilidade de formação de estoque do serviço turístico; assim, freqüentemente as empresas do setor se deparam com a existência de capacidade ociosa nos períodos de baixa estação e com limites à

\footnotetext{
${ }^{9}$ Como as operadoras turísticas responsáveis pela confecção dos pacotes são geralmente empresas de grande porte, que contam com a possibilidade de transacionar com vários hotéis em destinos turísticos consolidados, elas dispõem de grande poder de negociação para fixar as taxas de desconto sobre os preços de compra dos serviços hoteleiros.

${ }^{10}$ Williams \& Shaw (1991)

${ }^{11}$ Esse problema costuma ser agravado pela dependência que essas empresas têm das operadoras de turismo, que são suas grandes demandantes mesmo em períodos de alta estação e dispõem de forte poder de negociação sobre os preços dos serviços que compram.
} 
expansão da oferta de seus serviços turísticos nas fases de alta estação, quando a demanda pode ser excessiva em relação à capacidade disponível.

De modo geral, os destinos turísticos costumam promover políticas para desenvolver o setor em seus territórios. E mesmo que se trate de um destino consolidado, as instituições voltadas para o fomento dessa atividade procuram revitalizar a imagem de seus produtos turísticos, para evitar que os mesmos se tornem obsoletos e passem a ser menos procurados por turistas. Caso o propósito seja captar visitantes estrangeiros, então as políticas de desenvolvimento do setor procurarão abrir novos canais de vendas nos mercados emissores, pois, no turismo, os consumidores precisam se deslocar até a destinação para que as exportações possam ser efetivadas. A proliferação de novos destinos no mercado internacional, que apresentem padrões semelhantes de serviços turísticos, aumenta a concorrência entre os mesmos para inserir seus produtos nos roteiros vendidos pelas grandes operadoras.

A bibliografia citada neste item permite em parte explorar a questão da especulação em determinadas economias, que podem inicialmente ser classificadas como de "alto crescimento", recorrendo a Dymski (1998). Inicialmente se supõe que essas economias se caracterizam por serem destinos turísticos que atraem também visitantes estrangeiros e aplicadores interessados em incorporar esses territórios às estratégias de expansão de seus portfólios. Com base em Davidson (1978), parece razoável considerar que a prevalência de especuladores estrangeiros altistas no mercado imobiliário de uma dessas economias pode contribuir decisivamente para desencadear a emergência de uma bolha, alimentada pelo desempenho das instituições de crédito que operam no país ao qual tal destino pertence.

\section{Indicadores da Existência de Especulação no Mercado Imobiliário de Destinos}

\section{Turísticos}

A análise da evolução do mercado imobiliário em destinos turísticos requer a consideração de indicadores que possam oferecer indícios de existência de fortes movimentos especulativos. Para tanto é indispensável proceder à seleção de amostras em bairros da referida localidade que captem informações de seus mercados ao longo de determinado período de tempo, incorporando os seguintes dados: 
a.1) preços à vista dos imóveis prontos vendidos no mercado primário (imóveis novos que ainda não foram usados);

b.1) preços à vista dos imóveis prontos vendidos no mercado secundário (imóveis usados);

c.1) preço forward (futuro) para entrega futura (preço hoje de um imóvel na planta).

Convém ressaltar que "a.1" e "c.1" são mercados diferentes, intermediados no tempo pela taxa de juros - o diferencial entre eles é regido pela taxa de juros para o período equivalente, sendo influenciado também pela percepção da diferença de risco. Uma avaliação entre os dois mercados deve ser pautada pela consideração da diferença entre o preço do imóvel na planta (pagamento imediato ou parcelado contra entrega futura) e o preço do imóvel pronto no mercado primário. Que pode ser vista pela seguinte fração: (Preço do imóvel pronto - Preço do imóvel na planta) / Preço do imóvel na planta. A mesma constitui uma espécie de "taxa de juros do mercado imobiliário".

Desse modo, a empresa produtora do imóvel vai comparar a "taxa de juros do mercado imobiliário" descrita acima com uma taxa de juros de referência - em se tratando de um destino turístico brasileiro pode ser considerada a SELIC ou mesmo a taxa paga por algum fundo de aplicação -, para avaliar se compensa vender o imóvel na planta ou o imóvel pronto.

Caso a "taxa de juros do mercado imobiliário" seja positiva, a empresa deve considerar a seguinte situação: se ela resolver vender o imóvel na planta mais barato receberá em contrapartida o adiantamento de recursos por parte do cliente, que ela poderá aplicar no mercado financeiro, ganhando o juro acumulado até a data de entrega do imóvel. Contudo, essa venda do imóvel na planta implica em que ela perde ou deixa de ganhar a "taxa de juros do mercado imobiliário", dada pelo diferencial entre o preço do imóvel pronto e o preço da planta, dividido pelo preço do imóvel na planta. Ela deve analisar as expectativas que tem acerca das duas situações para ver qual caso compensa.

Ressalta-se que quando a taxa de juros de referência é superior a "taxa de juros do mercado imobiliário", é vantajoso para a construtora vender o imóvel na planta e fazer uma aplicação dos recursos no mercado financeiro. Ao mesmo tempo em que convém salientar que o diferencial de preço a favor do imóvel pronto é um indicador da atratividade das novas construções: para a empresa produtora interessa que o preço do imóvel pronto seja superior ao 
preço do imóvel na planta (ou seja, que a "taxa de juros do mercado imobiliário" seja positiva). Quando essa diferença é substancial pode ser indicadora de um forte movimento especulativo desencadeador de uma bolha ${ }^{12}$.

Outro tipo de evidência acerca do comportamento do mercado imobiliário pode ser extraído a partir do exame da seguinte razão: número de operações de vendas no mercado primário/ número de operações de vendas no mercado secundário. Uma diminuição desta relação no tempo pode ser considerada uma evidência do crescimento da especulação, pois tal tendência indica que o volume de transações no mercado secundário (imóveis de "segunda mão") cresceu em relação ao total de transações no mercado primário (imóveis novos ainda não usados).

Outro indicador do comportamento dos preços em uma destinação turística pode ser obtido a partir da adaptação do modelo teórico conhecido na literatura como q de Tobin. Em seu propósito original, Tobin (1969) analisa os canais pelos quais a política monetária pode afetar o investimento, mas seu modelo permite observar como a especulação financeira, ao afetar o nível de preços dos ativos, tem impacto sobre os gastos com investimento e a demanda agregada da economia. Em sua formulação, ele considera que existem dois preços: Pk, que representa o preço do capital pré-existente (índice de preço das ações); e P, que corresponde o preço dos bens de capital novo (índice geral de preços para a economia inteira). Assim o q de Tobin é dado pelo coeficiente $\mathrm{Pk} / \mathrm{P}$. Caso $\mathrm{Pk}$ supere $\mathrm{P}$, de modo que o coeficiente q seja maior que 1 , o mecanismo de preços na economia opera no sentido de desestimular a aquisição de firmas pré-existentes no mercado acionário, favorecendo a construção de novas empresas e/ou expansão daquelas que já se encontram em operação (custo mais baixo para o investidor). Se, porém, $\mathrm{Pk}$ for inferior a $\mathrm{P}$, indicando que o coeficiente q é menor que 1, o sistema de preços estimula a compra de empresas através do mercado acionário, pois o custo de construção de novas firmas ou a expansão das empresas pré-existentes torna-se mais elevado.

\footnotetext{
${ }^{12}$ Quando se considera o preço a prazo para cada mercado, a razão (preço a prazo - preço à vista) / preço à vista também deve ser comparada a uma taxa de juros de referência. Caso este índice seja maior que a taxa de juros, os demandantes dos imóveis terão incentivos para comprá-los à vista, pois o custo do financiamento no mercado para compra do imóvel é menor que o custo do financiamento cobrado pelo construtor. Na suposição que o demandante disponha de recursos próprios, os rendimentos do mercado financeiro serão inferiores ao ganho decorrente do desconto de preços obtidos na compra à vista.
} 
Com base no aludido modelo é possível observar que um movimento especulativo em torno das ações, cuja oferta é inelástica no curto prazo, tende a elevar seus preços que são muito sensíveis às variações da demanda, o que pode contribuir para aumentar o investimento, a produção, o emprego e a renda real. Esse processo, ao realimentar a demanda por ações, provoca novas subidas de preços e sua continuação por períodos sucessivos pode levar à formação de bolhas. A adaptação desse modelo ao exame do mercado de imóveis é possível porque neste último opera um mecanismo similar ao descrito no caso das ações. Os imóveis apresentam oferta inelástica no curto prazo por serem relativamente longos os períodos de produção associados à sua construção e os seus preços são também muito sensíveis às variações de demanda.

Assim, o q de Tobin pode ser obtido ao se comparar a evolução do preço spot do mercado secundário e do mercado primário com o custo da construção civil. Se o preço spot subir acima do custo da construção civil (o custo por metro quadrado) tem-se uma indicação de que o aludido coeficiente é maior que 1 . O q de Tobin maior que 1 é indicador de boom, e se for muito maior que 1 e crescente no tempo é indicador de bolha.

Caso a evolução dos indicadores discutidos acima aponte para a ocorrência de uma "bolha imobiliária" no destino turístico considerado, a questão a ser investigada a seguir é identificar os determinantes de sua geração, sustentação e as possibilidades de sua ruptura, com base na bibliografia relacionada e na consideração das especificidades da organização do mercado imobiliário.

\section{Mercado Imobiliário: fatores associados à oferta e demanda}

O tratamento do setor imobiliário requer que se decomponha sua análise entre os ofertantes, demandantes, produtos transacionados e instituições que operam no mercado. Essas últimas podem ser classificadas segundo a forma de atuação: as que definem regulamentos para operações no mercado fundiário e para a construção civil, as que provêem equipamentos e serviços de infraestrutura urbanísticos, e ainda, as que fornecem crédito para empresas e compradores de imóveis em geral. 
Com relação às empresas que operam no setor, é possível identificar uma organização similar à existente em uma cadeia produtiva, cuja composição, grosso modo, apresenta a seguinte configuração: o primeiro elo da cadeia é constituído por empresas ou pessoas físicas ofertantes dos terrenos nos quais serão construídos os imóveis; o seguinte, por empresas incorporadoras (compradoras dos terrenos e dos serviços de construção); o próximo elo é composto por empresas de construção civil, responsáveis pela edificação e entrega dos imóveis; e o elo seguinte, por imobiliárias, responsáveis pela oferta de imóveis prontos para venda e locação e lançamentos de novos imóveis.

É interessante explorar as relações contratuais típicas que se observam no interior dessa cadeia. A literatura clássica sobre o tema costuma chamar atenção para o papel da empresa incorporadora, que compra os terrenos dos proprietários fundiários, planeja os empreendimentos imobiliários, e assume a responsabilidade pelo financiamento da construção dos imóveis que serão postos à venda (Ribeiro, 1997). Nestas circunstâncias, pode-se dizer que parte da demanda por construção de imóveis é realizada no próprio interior da cadeia, pelos incorporadores, que irão avaliar, inclusive, a conveniência de vender um percentual dos imóveis ainda na planta. Nos períodos de intenso crescimento da construção civil, na fase de um boom imobiliário, existe estímulo para que as empresas de construção civil procedam à verticalização de suas atividades e operem também no segmento de incorporação, procurando ainda fazer estocagem de terrenos passíveis de serem utilizados para construção. Desse modo, elas irão se apropriar dos lucros gerados no processo de incorporação.

Alguns aspectos do processo de construção civil devem ser analisados. Inicialmente, convém examinar a questão fundiária: os terrenos sobre os quais serão feitas edificações constituem bens não-reprodutíveis, que podem ser demandados, inclusive, como reserva de valor. Essa predisposição a reter terrenos cresce quando seus proprietários têm expectativas dos mesmos localizarem-se em áreas próximas a espaços urbanos vazios, que serão intensamente valorizados pela construção de infraestrutura. Como observa Ribeiro:

Um construtor não pode decidir, de fato, produzir em espaços ainda não dotados dos necessários equipamentos coletivos e da infraestrutura, já que individualmente não poderá produzir esse conjunto de objetos imobiliários. Ele estará constrangido a procurar terrenos situados nos pontos da cidade onde preexistam esses elementos ou existirão num futuro próximo. Esta 
limitação de alternativas para a construção de moradias torna maior o poder monopolista dos proprietários dos terrenos "construtíveis", tornando o problema fundiário enfrentado pelo capital nesse setor não só qualitativamente diferente, quanto quantitativamente maior. (RIBEIRO, 1997, p. 88)

Neste sentido, a especulação imobiliária é estimulada pelo fato da estocagem de terrenos, ao assegurar a retenção de espaços vazios fora do mercado, aumentar a escassez desses bens durante a fase de crescimento da urbanização. O cálculo que o proprietário do terreno fará é se os custos de carregamento desse ativo, inclusive de pagamentos de impostos, serão compensados pelos ganhos de capital que espera realizar quando for vender o terreno a um preço estimado supostamente mais alto.

$\mathrm{O}$ agente incorporador quando pensa em adquirir o terreno para construir, por sua vez, considera o custo de sua aquisição e o custo de carregamento esperado e, por outro lado, estima os custos associados ao processo de incorporação, que envolve o custo de financiamento da construção, os custos operacionais e de financiamento ao comprador. Após o qual, ele compara com as receitas esperadas da venda dos imóveis construídos. Os ganhos de incorporação serão maiores se o agente antecipar corretamente o aumento da escassez dos terrenos e realizar a compra dos mesmos antes que as áreas nas quais os imóveis serão construídos se valorizem. Neste caso, ele poderá se beneficiar também do provável aumento de preços que esses bens alcançarão em decorrência de sua localização. Este agente, portanto, especula nas duas pontas, na aquisição do terreno e na venda do imóvel, assumindo ainda a estrutura de financiamento da construção. E ainda, pode operar em mercados forward e spot.

A empresa de construção civil que formaliza um contrato de construção e entrega de imóveis ao incorporador opera com um preço pré-estabelecido, tipicamente em mercados forward. Contudo, quando se considera todos os contratos que ela assume em um determinado período é necessário levar em conta os pesados custos fixos (que independem do nível de produção) associados ao tamanho de sua planta. Como essas empresas não formam estoques de produtos finais, ao contrário das incorporadoras, o ajuste entre oferta e demanda no período de mercado 
não pode ocorrer por meio da variação da quantidade estocada. Assim, uma variação na quantidade demandada pode suscitar como resposta uma variação na quantidade produzida. ${ }^{13}$

A construção de uma obra sob encomenda reduz o risco de mercado do empreendimento (de se executar essa venda em período de retração de mercado, o que provocaria queda de seu preço). Todavia, como ocorre em qualquer mercado em que uma empresa opere como fornecedora e a outra como demandante, os ganhos de cada uma delas dependerão do poder de negociação que disponham no momento de assinatura do contrato. Neste sentido, caso a incorporadora seja uma empresa de grande porte e o número de construtoras seja elevado, cresce o poder de barganha da primeira em estabelecer um preço de compra do serviço que seja mais compatível com os seus interesses. Na suposição inversa, de ser pequeno o número de empresas construtoras e reduzido o tamanho do agente incorporador, aumenta o poder de negociação das primeiras. Há que se considerar ainda, que se o mercado imobiliário estiver fortemente aquecido, os incorporadores que têm interesse de vender o maior número possível de imóveis se inclinarão a pagar preços mais elevados pelo metro quadrado construído, tanto mais porque o período de produção associado à construção do imóvel é relativamente longo quando comparado aos períodos de produção dos bens duráveis típicos.

As imobiliárias cumprem um papel importante na negociação dos imóveis prontos, elas aprofundam o mercado de imóveis de segunda-mão, dando liquidez ao mesmo. Os ganhos dessas empresas decorrem das comissões referentes à realização de contratos de locação e vendas.

A observação da cadeia do setor imobiliário permite identificar a demanda gerada pelos próprios agentes e empresas do setor. Mas existem outros demandantes que devem ser considerados. Em se tratando de um destino turístico, esta demanda pode ser gerada por aplicadores de outras nacionalidades e por investidores nacionais, além dos próprios moradores e aplicadores locais. A demanda gerada por estrangeiros pode ser motivada pela busca da segunda residência, em um contexto no qual os ativos (terrenos e imóveis) denominados em moeda nacional sejam suficientemente baratos para atraí-los. Mas,

\footnotetext{
${ }^{13}$ Se a queda no número de encomendas implica no aumento da capacidade ociosa, uma estratégia possível para a empresa pode ser alugar suas máquinas e equipamentos ociosos. $\mathrm{O}$ aumento na demanda por contratos pode resultar em uma busca por aumento da capacidade produtiva da empresa, que poderá considerar a conveniência de alugar máquinas e equipamentos necessários para aumentar a quantidade de imóveis construídos.
} 
freqüentemente envolve um cálculo de retorno de sua incorporação ao portfólio do agente, uma vez que exista expectativa que o mesmo possa gerar rendimentos na forma de aluguel no período do ano em que estiver ocioso.

É necessário ainda considerar os vultosos empreendimentos imobiliários que exigem grandes extensões de terras para suas edificações. Em períodos de forte aquecimento do mercado, o volume de compras e a freqüência com as quais as mesmas são feitas pressionam os preços dos terrenos e criam expectativas de valorização das áreas circunvizinhas aos empreendimentos, cujas construções impulsionam também a indústria da construção civil. A demanda internacional pode ser reforçada por arranjos estabelecidos entre as incorporadoras locais e as imobiliárias dos principais países emissores de turistas para esse mercado, sendo também afetada pelo comportamento da taxa de câmbio, posto que uma desvalorização real da moeda de uma destinação tanto estimula as exportações turísticas quanto barateia os ativos denominados nela. As incorporadoras de destinos turísticos localizados em regiões periféricas que sejam bem sucedidas nas vendas de imóveis em países emissores que disponham de moedas fortes podem se capitalizar em condições bastante vantajosas para financiar a construção de seus empreendimentos na moeda local.

Ao lado da demanda estrangeira, as "economias de alto crescimento" que são destinos turísticos podem ter seus mercados imobiliários aquecidos pelo aumento da demanda dos visitantes domésticos. O próprio crescimento do nível de atividade econômica impulsionado pela construção civil e pelo crescimento do turismo funciona com uma espécie de atrator para visitantes de outras regiões do país, que identificam oportunidades de investimento especialmente na área de serviços. $\mathrm{O}$ aumento das populações nesses destinos, decorrente de processos de migração, pressionam os mercados de moradia. Mas, a demanda por imóveis pode crescer também pela aplicação de indivíduos que conheceram a destinação e resolveram adquirir um apartamento ou flat que pretendem ocupar em apenas alguns meses do ano e alugar nos períodos em que não estiverem na destinação.

Os preços alcançados pelos imóveis transacionados no mercado imobiliário tendem a despertar o interesse dos nativos, que identificam nessas aplicações grandes perspectivas de ganhos. É preciso considerar que alguns indivíduos podem adquirir imóveis principalmente como uma forma de reserva de valor, como uma aplicação segura por ser um ativo tangível. 
Mas outros certamente serão movidos pela intenção de especular, sendo "mais altistas que o mercado em relação ao futuro" (DAVIDSON, 1978, p. 108), e buscam na aplicação em imóveis uma forma de valorizar sua riqueza.

A combinação dessas três fontes de demanda no mercado imobiliário - externa, de aplicadores nacionais e locais - influencia as decisões estratégicas das empresas incorporadoras, pois permite que elas possam explorar diferentes nichos de mercados: determinados empreendimentos serão voltados para atrair turistas estrangeiros, outros deverão focalizar tanto os visitantes estrangeiros quanto os nacionais, e alguns deles podem ainda ser destinados à população local. Ademais, empresas do setor imobiliário como incorporadoras e construtoras que operam em outras regiões do país se sentirão predispostas a desenvolver suas atividades no mercado local, contribuindo para aumentar o influxo de riqueza que entra no destino turístico.

Em se tratando propriamente dos produtos transacionados no mercado imobiliário, é possível identificar diferenças acentuadas segundo o destino a ser dado ao imóvel, que, grosso modo, pode ser utilizado como moradia, para fins comerciais, e ainda como unidade habitacional em empreendimentos turísticos. Essa diversidade de uso supõe a existência de uma forte heterogeneidade entre esses bens - cuja raiz encontra-se na vinculação do imóvel "com o espaço urbano (e não somente com o terreno) diferenciado objetiva e subjetivamente" (RIBEIRO, 1997, p.118) -, e se manifesta por meio de distintos preços de mercado. A segmentação de mercados ocorre inclusive entre imóveis destinados ao mesmo uso. Como observa Ribeiro:

A segmentação do mercado tornará possível a formação de preços de mercados diferenciados, não determinados pela concorrência entre todos os produtores, já que cada um estará ofertando no mercado utilidades diferenciadas: aqui a "privacidade", lá o "verde", acolá a "praia", mais adiante um menor tempo de transporte, ou, por outro lado, um endividamento menos pesado, mais compensador do ponto de vista econômico ou mais adequado às perspectivas de rendimento futuro do comprador. (RIBEIRO, 1997, p. 118). 
Convém explorar essa questão da heterogeneidade dos imóveis, pois Davidson (1978) observa que a baixa organização dos mercados spot para vários ativos de capital fixo decorre da "carência de uniformidade desses bens" (DAVIDSON, 1978, p. 93). Ocorre, porém, que no caso dos bens de capital a questão da especificidade se coloca de forma bastante intensa: uma máquina serve apenas a determinados processos produtivos, o que restringe significativamente o número de seus potenciais demandantes. Ademais, em se tratando de equipamentos de capital fixo, o problema da safra tecnológica emerge e contribui para restringir as opções dos aplicadores em capital produtivo, que precisam levar em conta a capacidade competitiva de suas plantas, que depende da tecnologia incorporada a seus equipamentos. No caso dos imóveis, as diferenciações entre os ativos não são tão amplas quando se leva em conta o critério de finalidade de uso: no limite, um imóvel residencial pode servir a moradia tanto quanto qualquer outro, em que pesem as diferenças de preços que possam existir em decorrência da localização, tamanho e de terem sido construídos em anos diferentes. Desse modo, é possível observar a existência de mercados spot para imóveis, com as imobiliárias cumprindo um papel importante para conferir liquidez a tais mercados.

Outro fator importante que influencia a oferta de novos produtos no mercado e tem impactos sobre o grau de valorização dos estoques disponíveis é a intervenção do Estado no espaço urbano, por meio de suas instituições. Através do marco regulatório elas

(...) fixam regras que estabelecem a relação entre superfície do terreno e a quantidade de metros quadrados passível de construção. Estas regras impõem um conjunto de limitações ao ato de construção que influenciam o uso econômico dos terrenos: alinhamento, gabarito, altura mínima dos apartamentos, áreas coletivas, etc. (RIBEIRO, 1997, p.123).

As instituições quando definem a cobrança de impostos territoriais e fixam as regras para construção afetam tanto o custo de carregamento dos bens quanto as expectativas dos agentes acerca das taxas de apreciação dos mesmos. Ao prover a um espaço vazio a infra-estrutura necessária à construção de moradias e de estabelecimentos comerciais, elas sinalizam a emergência de novos terrenos acessíveis à especulação imobiliária. Assim como a inadequada manutenção do sistema de infraestrutura em áreas antigas contribui para chancelar a 
decadência das mesmas. Por outro lado, a promoção de políticas de revitalização de antigos centros comerciais pode fornecer novos impulsos à construção nas suas imediações.

As instituições com suas restrições regulatórias em algumas áreas e suas políticas de incorporação sistemática de novos espaços aos investimentos imobiliários - proporcionados pela provisão de infraestrutura nos mesmos - influenciam na disponibilidade de terrenos apropriados à construção. Como os novos terrenos são pré-requisitos indispensáveis à construção, a oferta dos mesmos condiciona o fluxo de produção dos novos produtos imobiliários. Neste sentido, parece razoável supor que as instituições com seus regulamentos urbanísticos, em contexto de elevado crescimento da demanda, podem operar no sentido de contribuir para o aumento ou redução da escassez dos mercados de imóveis.

Os fluxos de produção de novos produtos imobiliários e os volumes de transações dos estoques de imóveis existentes costumam ser afetados também pelas condições de financiamento. Ressalta-se que o crédito é importante tanto para financiar as atividades de incorporação e construção quanto as vendas dos imóveis nos mercados primários e secundários. Os gastos com investimentos imobiliários irão variar de acordo com os tipos de empreendimentos, a área construída, e o material utilizado. Em destinos turísticos consolidados, os empresários do setor freqüentemente realizam vultosos gastos com a construção de hotéis e condomínios para atrair turistas. Trata-se, em geral, de empreendimentos com longo prazo de maturação, e que exigem estruturas de crédito apropriadas à evolução dos negócios para evitar que um descasamento temporal entre as maturidades de seus ativos e passivo comprometa o retorno de sua aplicação.

Vários países em desenvolvimento que têm regiões turísticas costumam fomentar a expansão dos negócios do setor concedendo crédito para o mesmo. E com freqüência, eles privilegiam os empreendimentos hoteleiros para ofertar empréstimos a taxas de juros preferenciais, mais baixas que as praticadas no mercado. Este segmento da oferta turística costuma ser alvo do crédito dirigido por melhor definir as possibilidades de inserção de um dado destino turístico nas grandes redes de comercialização internacionais e domésticas. Ademais, a construção de um hotel costuma exigir financiamento de longo prazo, em decorrência do extenso período de maturação dessa inversão. (Mendonça e Bezerra, 2007). 
De maneira geral, os empreendimentos do setor imobiliário exigem crédito de longo prazo, tanto para financiar as construções quanto para fornecer recursos em condições adequadas às compras dos bens produzidos. Afinal, os mesmos são ativos onerosos, com longos períodos de vida útil. Neste sentido, o desenvolvimento de instituições de crédito voltadas para atender os distintos agentes é condição indispensável: i) ao aumento da oferta de novos produtos imobiliários; e ii) a sustentação de elevados níveis de demanda pelos produtos novos e usados. Assim, a expansão das operações de crédito imobiliário contribui para o aquecimento do mercado imobiliário, constituindo-se em um condicionante interno do mesmo.

Outro aspecto que pode influenciar as condições de financiamento do setor imobiliário é o grau de organização do mercado de capitais. Supondo a existência de mercados de capitais organizados, caso o destino turístico adote uma política monetária que eleve a taxa de juros básica doméstica vis-à-vis às taxas praticadas por outras economias, ele tenderá a atrair aplicações de portfólio em títulos públicos e privados. A adoção por longos períodos dessas políticas pode contribuir para aprofundar os mercados de capitais, aumentando a liquidez dos mesmos. $\mathrm{O}$ aumento dessa liquidez pode abrir fontes adicionais para captação de recursos por parte das empresas de construção civil. ${ }^{14}$

É importante ver de perto a questão do aquecimento do setor imobiliário que, grosso modo, reflete uma relativa situação de escassez. Keynes, no capítulo 17 da Teoria Geral, chamou atenção para as duas propriedades da moeda que, segundo ele, contribuiriam para explicar a singularidade desse ativo, quais sejam, baixa elasticidade de produção e elasticidade de substituição igual a zero. Os produtos imobiliários talvez possam ser pensados à luz dessa abordagem, na suposição de que os mercados nos quais estão sendo transacionados localizamse em uma economia que se caracteriza por apresentar "alto crescimento" e ser um destino turístico consolidado.

A produção do setor imobiliário leva tempo e está sujeita às fortes restrições, como regulamentos urbanísticos e disponibilidade de terrenos. Neste sentido, parece razoável

\footnotetext{
${ }^{14}$ Esse parece ser o caso da evolução recente dos mercados de capitais no Brasil. A possibilidade de obter financiamento parece ter motivado a colocação de vários tipos de papéis nesses mercados nos anos de $2004 \mathrm{e}$ 2005. Sant'anna (2006). Contudo, deve ser ressalvado que, do ponto de vista da oferta, taxas de juros elevadas costumam afetar negativamente as perspectivas de lançamento de novos títulos emitidos pelas empresas. Mas no Brasil, pode se especular que esses agentes demandantes talvez tenham se acostumado a aplicar nesses mercados, pois, a despeito da queda da taxa de juros observada nos últimos meses de 2006, eles continuaram aplicando no mercado doméstico.
} 
considerar que a oferta de novos produtos não pode se ajustar rapidamente ao incremento substancial da demanda dos mesmos (dispondo assim da característica de baixa elasticidade de produção). Tanto mais, quando se considera as economias em que as empresas construtoras estão sendo requisitadas simultaneamente para atender as solicitações de construção de imóveis para moradia e concomitantemente também implantar gigantescos empreendimentos imobiliários e turísticos. Caso tais empresas estejam operando no limite de sua capacidade, o aumento de demanda por imóveis novos encontrará maiores restrições para ser prontamente atendido.

Quando se trata de imóveis, é interessante examinar aqueles voltados para moradias, pelas especificidades que carregam. Embora esses ativos possam servir de objeto de especulação em economias de "alto crescimento" que sejam também destinos turísticos, há um aspecto que precisa ser considerado: tais economias costumam atrair imigrantes e migrantes para o seu território. Assim, mesmo que se considere a motivação especulativa para a demanda por imóveis por parte de sua população, o fato é que as pessoas realmente precisam de bens que sirvam aos propósitos de habitação, que devem ser comprados ou alugados para essa finalidade (característica que indica elasticidade de substituição igual a zero).

As considerações feitas nos três últimos parágrafos não têm a intenção de requisitar uma equivalência entre o papel da moeda e dos imóveis, o que de resto seria um absurdo, mas tão somente explorar as especificidades dos últimos para compreender um processo de especulação em destinos turísticos. Nessas economias, em algumas ocasiões a escassez dos imóveis para moradia pode ocorrer de forma mais intensa.

Para avançar na compreensão do funcionamento do mercado de imóveis é conveniente examiná-lo à luz do modelo de mercados que operam com preços flexíveis, apresentado em Macedo e Silva (1999). O mesmo constitui uma referência apropriada uma vez que no setor de imóveis, o volume de estoques é consideravelmente superior ao fluxo de novos imóveis produzidos, e parte dele pode estar concentrado nas carteiras de agentes que têm o propósito de especular. Em economias de "alto crescimento" que são destinos turísticos, a predisposição dos agentes a especular com esses ativos tende a aumentar quando o fenômeno de uma bolha imobiliária já está em curso nos principais países emissores de turistas para os mesmos e as aplicações nos mercados locais constituem uma alternativa bastante interessante para esses 
visitantes. Essa tendência será reforçada pelo movimento de alta de preços resultante do aumento de demanda.

O crescimento populacional derivado do aumento de visitantes que decidem morar na destinação contribui para expandir a demanda. Os especuladores antecipando novos aumentos de preços, em decorrência do aumento da procura dos ativos, ampliam suas posições nesses bens. $\mathrm{O}$ incremento da demanda pode se sustentado por crédito abundante e relativamente barato, que cresce em ritmo superior a oferta de terrenos e dos novos produtos imobiliários. A combinação de um fluxo de produção pequeno, em relação à demanda por novos imóveis, e o aumento da retenção de estoques dos imóveis usados para fins especulativos resulta em uma significativa elevação dos preços desses ativos transacionados no mercado, refletindo o aumento da escassez dos mesmos. Em tais circunstâncias a economia de "alto crescimento" se transforma em "economia de bolha", sendo conveniente então considerar as condições que podem provocar a ruptura dessa bolha.

\section{Conclusão}

A emergência de bolhas em destinos turísticos depende, conforme visto, da inserção internacional dessas economias nos circuitos de comercialização das grandes operadoras de turismo e de determinantes internos - dados pelo comportamento da oferta e das instituições que definem o marco regulatório local, pelo aumento da demanda de visitantes domésticos, pela expansão do crédito dirigido para financiar a construção e a demanda crescente de imóveis, bem como pelas oportunidades abertas para captação de recursos nos mercados de capitais. O crescimento da demanda por imóveis nos mercados locais é também decorrente da demanda dos nativos e migrantes que resolvem morar no destino. O aquecimento da demanda em contexto de crescimento insuficiente da oferta contribui para a subida de preços, alimentando os movimentos especulativos geradores de bolha. A constatação de ocorrência de uma bolha no mercado imobiliário pode ser obtida a partir do levantamento de informações que gerem os indicadores propostos no item 3 .

A possibilidade de ruptura da bolha dependerá também tanto dos fatores externos quanto dos fatores internos. Com relação aos primeiros, a queda do número de visitantes estrangeiros e turistas de outras regiões diante da oferta excessiva de empreendimentos turísticos e 
imobiliários pode provocar a desvalorização dos mesmos, contribuindo para o aparecimento de algo próximo as "cidades fantasmas" (pelo menos nos bairros nos quais se localizam os empreendimentos turísticos). Este quadro, por sua vez, pode implicar perda do poder de atração dos produtos turísticos locais e ocasionar uma redução mais acentuada da demanda por imóveis na destinação. Por outro lado, a ruptura da bolha pode ser desencadeada pela contração do crédito e de seu encarecimento e pela perda de liquidez do mercado de capitais. A desvalorização do estoque de riqueza dos agentes que concentraram suas posições nesses ativos pode desencadear um abrupto movimento de venda, inclusive para liquidar as obrigações decorrentes dos financiamentos tomados.

Embora existam interesses convergentes entre certos segmentos do turismo e do setor imobiliário, há também tensões e conflitos entre eles. A construção dos grandes empreendimentos imobiliários e a compra de imóveis por estrangeiros e turistas do próprio país tendem a diminuir a taxa de ocupação de grande parte da rede hoteleira local. O que não é problema trivial, quando se considera o fenômeno da sazonalidade no setor, que impõe a concentração da maior parte das receitas geradas em alguns poucos meses do ano e a distribuição de despesas de custo fixo ao longo do ano.

Para evitar a ruptura de uma bolha e contemplar minimamente os interesses de grande parte dos empreendimentos hoteleiros, os organismos fomentadores de turismo têm de investir na imagem do destino para abrir, em ritmo cada vez mais acelerado, novos canais de comercialização em mercados emissores internacionais e nacionais. Contudo, se esses turistas continuarem a comprar imóveis nesses destinos, o problema de queda nas taxas de ocupação dos hotéis continua com o crescimento da oferta de novas alternativas de acomodação, recolocando a ameaça de ruptura da bolha. A bolha imobiliária pode estourar em função de mudanças observadas no grau de inserção dessas economias no mercado internacional de turismo e/ou de alterações no desempenho da economia doméstica e de suas instituições de crédito, bem como de seus mercados de capitais. 


\section{Referências}

COUTINHO, L. M.; NASCIMENTO M.M. Crédito habitacional acelera o investimento habitacional no país. In: TORRES FILHO, E. T.; PUGA, F. P.; FERREIRA, F. M. R. (orgs). Visão do desenvolvimento. Rio de Janeiro: BNDES, p. 141-149, 2006.

CRUZ, R.M. de C. Politica de turismo e território. São Paulo: Ed. Contexto, 2001.

DAVIDSON, P. Money and the real world. Basingstoke: MacMillan, 1978.

DYMSKI, G.A. "Economia de bolha" e crise financeira no leste asiático e na Califórnia: uma perspectiva espacializada de Minsky. Economia e Sociedade, n.11, p. 73-134, dez. 1998.

FONSECA, M.A.P. Espaço, políticas de turismo e competitividade. Natal: Edufrn, 2005.

KEYNES, J.M. A Teoria Geral do Emprego, do Juro e da Moeda. São Paulo: Abril Cultural, 1982.

KINDLEBERGER, C. P. Manias, pânico e crashes: um histórico das crises financeiras. Rio de Janeiro: Nova Fronteira, 2000.

LAGE, B.H.G. e MILONE, P.C. A economia do turismo. Campinas: Papirus, 1991. MACEDO E SILVA, A.C. Macroeconomia sem Equilíbrio. Petrópolis: Vozes, 1999.

A montanha em movimento: uma notícia sobre as transformações recentes da economia global. In: CARNEIRO, R. (org) A Supremacia dos mercados e a política econômica do governo Lula. São Paulo: Editora UNESP, 2006.

MENDONÇA, A.R.R.; BEZERRA, M.M.O. "Políticas de financiamento: efeitos sobre a oferta e demanda dos serviços turísticos no Brasil". In: XII ENCONTRO NACIONAL DE ECONOMIA POLÍTICA, 2007, São Paulo. Anais ...São Paulo: XII ENCONTRO NACIONAL DE ECONOMIA POLÍTICA, 2007. 1 CD ROM.RIBEIRO, L.C.Q. Dos Cortiços aos Condomínios Fechados: as formas de produção da moradia na cidade do Rio de Janeiro. Rio de Janeiro: Civilização Brasileira e Ippur (UFRJ), 1997.

JORNAL TRIBUNA DO NORTE, 28/01/2007.

REVISTA ISTO É DINHEIRO. 28/02/2007.

REVISTA CARTA CAPITAL. 12/03/2008.

SANT'ANNA, A. A.. Crescimento de debêntures financia capital de giro. In: TORRES FILHO, E.T.; PUGA, F.P.; FERREIRA, F.M.R (orgs). Visão do Desenvolvimento. Rio de Janeiro: BNDES, p. 2328, 2006.

TOBIN, J. A General Equilibrium Approach to Monetary Theory. Journal of Money, Credit and Banking, 1: 15-29, 1969.

\section{Recebido em: 26/07/2011}

Aprovado em: 08/03/2012 (1 ${ }^{\mathrm{a}}$ versão) $06 / 06 / 2012$ ( $2^{\mathrm{a}}$ versão) 